\title{
Association of Nutritional Parameters with Clinical Outcomes in Patients with Acute Myeloid Leukemia Undergoing Haematopoietic Stem Cell Transplantation
}

\author{
Annic Baumgartner ${ }^{a, c}$ Noemi Zueger ${ }^{a, c}$ Annika Bargetzi ${ }^{a, c}$ \\ Michael Medinger ${ }^{d} \quad$ Jakob R. Passweg ${ }^{d}$ Zeno Stanga ${ }^{e} \quad$ Beat Mueller $^{a, c}$ \\ Mario Bargetzi ${ }^{b}$ Philipp Schuet $z^{a, c}$ \\ ${ }^{a}$ Medical University Department, Clinic for Endocrinology/Metabolism/Clinical Nutrition, and ${ }^{b}$ Clinic for \\ Hematology and Oncology, Kantonsspital Aarau, Aarau, ' ${ }^{\mathrm{C}}$ Medical Faculty of the University of Basel, and d Clinic for \\ Hematology, University Hospital Basel, Basel, and ${ }^{e}$ Department of Endocrinology, Diabetes and Clinical Nutrition, \\ Bern University Hospital, and University of Bern, Bern, Switzerland
}

\section{Key Words}

Myeloid leukemia $\cdot$ Nutrition · Malnutrition ·

Transplantation

\begin{abstract}
Introduction: In acute myeloid leukemia (AML) patients undergoing allogeneic haematopoietic stem cell transplantation (HSCT), there is uncertainty about the extent of influence nutritional parameters have on clinical outcomes. In this study, we investigated the association between initial body mass index (BMI) and weight loss during HSCT on clinical outcomes in a well-characterised cohort of AML patients. Methods: We analysed data of the Basel stem-cell transplantation registry ('KMT Kohorte') including all patients with AML undergoing first allogeneic HSCT from January 2003 to January 2014. We used multivariable regression models adjusted for prognostic indicators (European Group for Blood and Marrow Transplantation risk score and cytogenetics). Results: Mortality in the 156 AML patients (46\% female,
\end{abstract}

\section{KARGER}

E-Mail karger@karger.com

www.karger.com/anm mean age 46 years) over the 10 years of follow-up was $57 \%$. Compared to patients with a baseline BMI $\left(\mathrm{kg} / \mathrm{m}^{2}\right)$ of $20-25$, a low $\mathrm{BMI}<20$ was associated with higher long-term mortality (70 vs. $49 \%$, adjusted hazard ratio $1.97,95 \% \mathrm{Cl} 1.04-3.71$, $\mathrm{p}=0.036)$. A more pronounced weight loss during HSCT ( $>7$ vs. $<2 \%$ ) was associated with higher risk for bacterial infections (52 vs. $28 \%$, OR 2.8, 95\% Cl 0.96-8.18, $\mathrm{p}=0.059$ ) and fungal infections (48 vs. $23 \%$, OR 3.37, 95\% Cl 1.11-10.19, p= 0.032 ), and longer hospital stays (64 vs. 38 days, adjusted mean difference 25.6 days (15.7-35.5), $\mathrm{p}<0.001$ ). Conclusion: In patients with $\mathrm{AML}$, low initial BMI and more pronounced weight loss during $\mathrm{HSCT}$ are strong prognostic indicators associated with lower survival and worse disease outcomes. Intervention research is needed to investigate whether nutritional therapy can reverse these associations.

(c) 2016 S. Karger AG, Basel
(C) 2016 S. Karger AG, Basel

0250-6807/16/0692-0089\$39.50/0
Prof. Philipp Schuetz, MD, MPH

University Department of Medicine Kantonsspital Aarau

Tellstrasse, CH-5001 Aarau (Switzerland)

E-Mail schuetzph@gmail.com 


\section{Introduction}

Loss of appetite resulting in involuntary weight loss is a key symptom of severe illnesses, particularly in different types of malignant diseases [1]. Weight loss associated with malignant diseases may result directly from energy deprivation due to poor appetite and gastrointestinal failure but may also be due to dehydration and sarcopenia [2, 3]. Particularly, the inflammatory response observed in patients with malignant diseases has multiple effects on the brain leading to loss of appetite, as well as on the gastrointestinal tract with delays in gastric emptying [4-6]. Also, endocrine imbalances associated with malignant disease with increases in catabolic hormones (such as glucocorticoid hormones) and a decrease in anabolic hormones (such as testosterone and other sexual steroids) further enhance catabolism and aggravate malnutrition [1]. In addition, anti-cancer therapies may negatively affect nutritional intake due to mucositis and nausea [7]. Importantly, the relationship between malignant disease and cachexia may well be bi-directional, with malignancy and its treatment affecting nutritional status; also malnutrition may have a negative influence on recovery from disease and the course of illness $[8,9]$.

Patients undergoing allogeneic haematopoietic stem cell transplantation (HSCT) for acute myeloid leukemia (AML) are at eminent high risk for nutritional deterioration. Although AML patients frequently present with a normal nutritional status upon initial diagnosis of disease, they are at risk to experience significant weight loss during HSCT [7]. For this reason, the guidelines of the American and European Societies for Parenteral and Enteral Nutrition (APSEN, ESPEN) stress the importance of using nutrition-screening tools to identify those patients who require formal nutrition assessment with development of a detailed nutrition care plan [2, 3, 10-12]. They also state that nutritional treatment is appropriate in patients undergoing HSCT if they are malnourished at baseline or if it can be anticipated that patients are unable to ingest and/or absorb adequate nutrients for a prolonged period of time. There is, however, uncertainty about the influence of nutritional parameters at baseline and during HSCT on clinical outcomes in specific cancer populations, such as AML patients. Also, it remains unclear who among the patients undergoing HSCT do or do not ultimately benefit from nutritional treatment [13]. Identification of subgroups of patients at highest risk may help to close this gap.

Our aim was therefore to investigate associations of initial body mass index (BMI) and maximal weight loss during HSCT on mortality, and infectious complications in a well-characterised cohort of AML patients included in our patient registry over a 10-year time period. In an exploratory analysis, we also investigated differences in patients with or without nutritional therapy adjusting the analysis for important prognostic indicators.

\section{Methods}

\section{Study Design and Setting}

This is an observational cohort study including consecutive AML patients enrolled in the Basel stem-cell transplantation registry (KMT Kohorte) for undergoing first allogeneic HSCT from January 2003 to January 2014. Due to the observational character of this study, the Institutional Review Board of the University Hospital Basel (EKNZ) approved the study and waived the need for informed consent.

\section{Study Aims and Hypothesis}

The overall study aim was to investigate the interrelatedness of (a) BMI $\left(\mathrm{kg} / \mathrm{m}^{2}\right)$ before HSCT, (b) weight loss (\%) during HSCT, and (c) use of nutritional treatment on different patient-relevant outcomes. We hypothesised that low pre-transplantation BMI and a more pronounced weight loss during HSCT would be strong predictors for adverse outcomes, and that these associations may be reversed by use of nutritional therapy.

\section{Patient Population}

We included consecutive patients with a confirmed diagnosis of AML receiving HSCT at the University hospital Basel, Switzerland. This institution has been performing transplantations on patients right from 1973 [14] with a total of more than 2,000 transplantations being performed until now. Clinical practice concerning conditioning regime and supportive therapy has been successively implemented based on results of current research. Patients younger than 16 years were treated at the Universitäts-Kinderspital Beider Basel and were thus not considered for this analysis. Also, patients undergoing reduced-intensity conditioning, patients with other final diagnoses than AML and patients with autologous transplantation were excluded. In addition, we excluded all patients who underwent HSCT before 2003. If patients underwent more than one transplantation process during 20032014 , only the first transplantation episode was recorded and used for the analysis. From a total of 709 transplantations, 156 were patients with AML fulfilling the study criteria and were thus included in the final analysis.

\section{Definitions and Clinical Variables}

All clinical data were used from the KMT cohort file with completion by abstraction from the medical charts. To investigate initial BMI and outcomes, patients were classified as low BMI $(<20$ $\left.\mathrm{kg} / \mathrm{m}^{2}\right)$, normal BMI $\left(20-25 \mathrm{~kg} / \mathrm{m}^{2}\right)$ and high BMI $\left(>25 \mathrm{~kg} / \mathrm{m}^{2}\right)$. Weight loss during HSCT was defined as the relative difference (\%) between initial weight and minimal weight during the hospital stay. Patients were grouped according to their weight loss into little weight loss $(<2 \%)$, moderate weight loss $(2-7 \%)$ and high
Baumgartner/Zueger/Bargetzi/Medinger/ Passweg/Stanga/Mueller/Bargetzi/Schuetz 
weight loss (>7\%). Patients were also classified as receiving nutritional therapy or not with any route of support counting as having received nutritional therapy. Yet, based on the routine nutritional protocol used in the institution, all patients with nutritional therapy received parenteral nutrition (PE), except for one patient who received complementary enteral nutrition.

For all patients, we calculated the European Group for Blood and Marrow Transplantation (EBMT) risk score as recommended. Genetic risk was also assessed based on the recommendations by the Schweizerische Arbeitsgemeinschaft für klinische Krebsforschung obtained as a result of cytogenetic analyses and grouped into low, moderate or high risk.

\section{Endpoints}

The primary endpoint of the study was overall survival until follow-up. Patients were censored at the last time of follow-up if they did not die. Secondary endpoints included in-hospital mortality, mortality within the first 100 days after transplantation, time to engraftment, time to mucositis, time to development of fever (first episode), cumulative number of days with fever, recurrent episodes of fever, infections during hospital stay (including bacterial, viral and fungal infections), recurrence of disease, graft versus host disease (GvHD) of the intestinal tract and the skin, new diagnoses of infections 1 and 2 years after transplantation and secondary cancers within the follow-up period. Aplasia versus engraftment was defined as neutrophil granulocytes $<0.5 \times 10^{9}$ per litre or $>0.5 \times 10^{9}$ neutrophil granulocytes per litre, respectively.

\section{Statistical Analysis}

This report adheres to the STROBE guidelines for reporting observational studies [15]. Discrete variables are expressed as counts (percentage) and continuous variables as medians and interquartile ranges or means and SD as appropriate. Frequency comparison was done using the chi-square test. To assess the association of our main predictors and outcomes, we used regression models adjusted for main prognostic parameters including the EBMT risk score as well as cytogenetics. Other covariates included age, gender and comorbidities (coronary heart disease, valvular heart disease, congestive heart disease, diabetes, COPD, chronic kidney disease, chronic liver disease). We also adjusted the analysis regarding nutritional therapy with initial BMI and weight loss.

We used cox models for time-to-event data with reporting of hazard ratios (HRs), logistic regression for binary outcomes with reporting of ORs and linear regression for continuous outcomes with reporting of coefficients corresponding to mean differences.

We used STATA 12.1 (Stata Corp 2012, College Station, Tex., USA). All testing was 2 -tailed, with $\mathrm{p} \leq 0.05$ considered to indicate statistical significance.

\section{Results}

\section{Baseline Characteristics}

A total of 156 patients (46\% women, mean age 46 years) with a confirmed diagnosis of AML were included. The main source of stem cells was peripheral blood $(\mathrm{n}=$ 147), but 8 patients received stem cells from bone marrow and one patient received cord blood. The overall mortality rate was $57.1 \%(\mathrm{n}=89)$ with a mean time to death of 12 months (95\% CI 9-16) and a mean observation time in survivors of 72 months (95\% CI 62-82). Table 1 shows patient characteristics of the overall cohort, stratified by overall survival status.

\section{Association of Initial BMI and Outcomes}

According to the BMI before HSCT, 71 patients had normal BMI $\left(20-25 \mathrm{~kg} / \mathrm{m}^{2}\right), 20$ patients had low BMI $\left(<20 \mathrm{~kg} / \mathrm{m}^{2}\right)$ and 65 patients had high BMI $\left(>25 \mathrm{~kg} / \mathrm{m}^{2}\right)$. Overall mortality was significantly increased in patients with a low BMI before HSCT compared to normal BMI (70 vs. $49 \%)$ with a HR of 1.97 (95\% CI $1.04-3.71, \mathrm{p}=$ $0.036)$. There was no significant difference in mortality during the index hospital stay and within 100 days. Also, no increase in recurrence risk was found (table 2). When looking at infectious complications during the initial HSCT, low BMI tended to be associated with an earlier development of mucositis (HR 1.72, 95\% CI 1.00-3.00, $p=0.051$ ), while fever, fever days and infections had similar patterns of development. Also, outcomes after 1 and 2 years were similar in all groups.

\section{Association of Weight Loss and Outcomes}

There was a mean weight loss of $4 \%$ calculated from the initial weight before HSCT to the minimal weight during the index hospital stay. A more pronounced weight loss compared to little weight loss (reference group) during HSCT ( $>7$ vs. $<2 \%$ ) was associated with an earlier development of fever (HR 1.92, 95\% CI 1.09-3.38, $\mathrm{p}=0.025$ ) and more fever days (adjusted difference 3.45, 95\% CI 0.59-6.32, p = 0.018), as well as high risk for infectious complications including bacterial infections (52 vs. $28 \%$, OR $2.8,95 \%$ CI $0.96-8.18, \mathrm{p}=0.059)$ and fungal infections ( 48 vs. $23 \%$, OR $3.37,95 \%$ CI $1.11-10.19, \mathrm{p}=$ $0.032)$. Also, the length of stay was significantly increased (64 vs. 38 days, adjusted coefficient 25.6, 95\% CI 15.7$35.5, \mathrm{p}<0.001)$. A more pronounced weight loss was also associated with higher mortality during the index hospital stay (HR 5.59, 95\% CI 1.04-29.93, p = 0.044), but results were not significant for mortality within 100 days and overall survival.

\section{Outcomes in Patients Receiving and Not Receiving Nutritional Therapy}

In an exploratory analysis, we also investigated outcomes in patients who did receive nutritional treatment with patients who did not receive nutritional therapy. A total of 90 patients $(57 \%)$ received nutritional treatment 
Table 1. Patient characteristics

\begin{tabular}{|c|c|c|c|c|}
\hline & All patients & Overall-survivors & Overall-nonsurvivors & $\mathrm{p}$ value \\
\hline Number of patients & 156 & 67 & 89 & \\
\hline \multicolumn{5}{|l|}{ Socio-demographics and nutritional parameters } \\
\hline Age at HSCT, mean (SD) & $46.4(12.0)$ & $45.5(11.2)$ & $47.1(12.5)$ & 0.42 \\
\hline Initial BMI, $\mathrm{kg} / \mathrm{m}^{2}$, mean (SD) & $24.7(4.5)$ & $25.0(4.6)$ & $24.6(4.4)$ & 0.57 \\
\hline$<20$ & $20(12.8)$ & $6(9)$ & $14(16)$ & 0.16 \\
\hline$>25$ & $65(41.7)$ & $25(37)$ & $40(45)$ & \\
\hline Lowest BMI, $\mathrm{kg} / \mathrm{m}^{2}$, mean (SD) & $23.7(4.2)$ & $24.1(4.3)$ & $23.5(4.1)$ & 0.37 \\
\hline$<20$ & $32(20.5)$ & $11(16)$ & $21(24)$ & 0.54 \\
\hline $20-25$ & $72(46.2)$ & $33(49)$ & $39(44)$ & \\
\hline$>25$ & $52(33.3)$ & $23(34)$ & $29(33)$ & \\
\hline Weight loss during HSCT, $\%$, mean (SD) & $-4.0(3.0)$ & $-3.5(2.5)$ & $-4.4(3.3)$ & 0.077 \\
\hline TBI & $42(26.9)$ & $15(22)$ & $27(30)$ & 0.27 \\
\hline One HSCTs & $135(86.5)$ & $61(91)$ & $74(83)$ & 0.15 \\
\hline More than one HSCTs & $21(13.5)$ & $6(9)$ & $15(17)$ & \\
\hline \multicolumn{5}{|l|}{ Comorbidities } \\
\hline Coronary heart disease & $7(4.5)$ & $2(3)$ & $5(6)$ & 0.43 \\
\hline Congestive heart failure & $8(5.1)$ & $1(1)$ & $7(8)$ & 0.074 \\
\hline Valvular heart disease & $9(5.8)$ & $3(4)$ & $6(7)$ & 0.55 \\
\hline Diabetes mellitus & $6(3.8)$ & $3(4)$ & $3(3)$ & 0.72 \\
\hline COPD & $3(1.9)$ & $2(3)$ & $1(1)$ & 0.40 \\
\hline Chronic kidney disease & $5(3.2)$ & $2(3)$ & $3(3)$ & 0.89 \\
\hline Chronic liver disease & $17(10.9)$ & $7(10)$ & $10(11)$ & 0.88 \\
\hline
\end{tabular}

Values are $\mathrm{n}(\%)$ unless otherwise indicated.

during HSCT with all of them being treated with parenteral nutrition (including one patient also receiving complementary enteral nutrition) and 54 patients $(60 \%)$ receiving also glutamine as part of the nutritional intervention. This analysis was again adjusted for prognostic indicators as well as initial weight and weight loss during the index hospital stay. Compared to not receiving nutritional therapy, receiving parenteral nutrition was associated in the fully adjusted analysis with earlier time to engraftment, but also with worse clinical outcomes including higher mortality, higher risk for fever and infectious complications and also higher GvHD risk (Appendix 1). Also, there was a lower risk for infectious complications during the first and second year after HSCT. Glutamine use compared to using parenteral nutrition without glutamine had similar outcomes except for lower mucositis risk but a fourfold increase in clostridium difficile infection in the adjusted analysis (Appendix 2).

\section{Discussion}

Within this cohort of consecutive patients receiving HSCT for AML at a University centre in Switzerland, low initial BMI proved to be a strong and independent risk factor for overall mortality and development of mucositis, while a more pronounced weight loss during HSCT was associated with fever and infectious complications as well as mortality. Importantly, patients with a more pronounced weight loss also showed a marked increase in length of hospital stay that ranged from 28 to 64 days. These data are in line with previous studies from other centres and different patient populations and demonstrate the importance of an impaired nutritional status at the start as well as during HSCT as an unfavourable prognostic factor in this patient population.

Deterioration of nutritional status is a well-known and disease-independent risk factor across medical dis-
92

Ann Nutr Metab 2016;69:89-98 DOI: $10.1159 / 000449451$
Baumgartner/Zueger/Bargetzi/Medinger/ Passweg/Stanga/Mueller/Bargetzi/Schuetz 


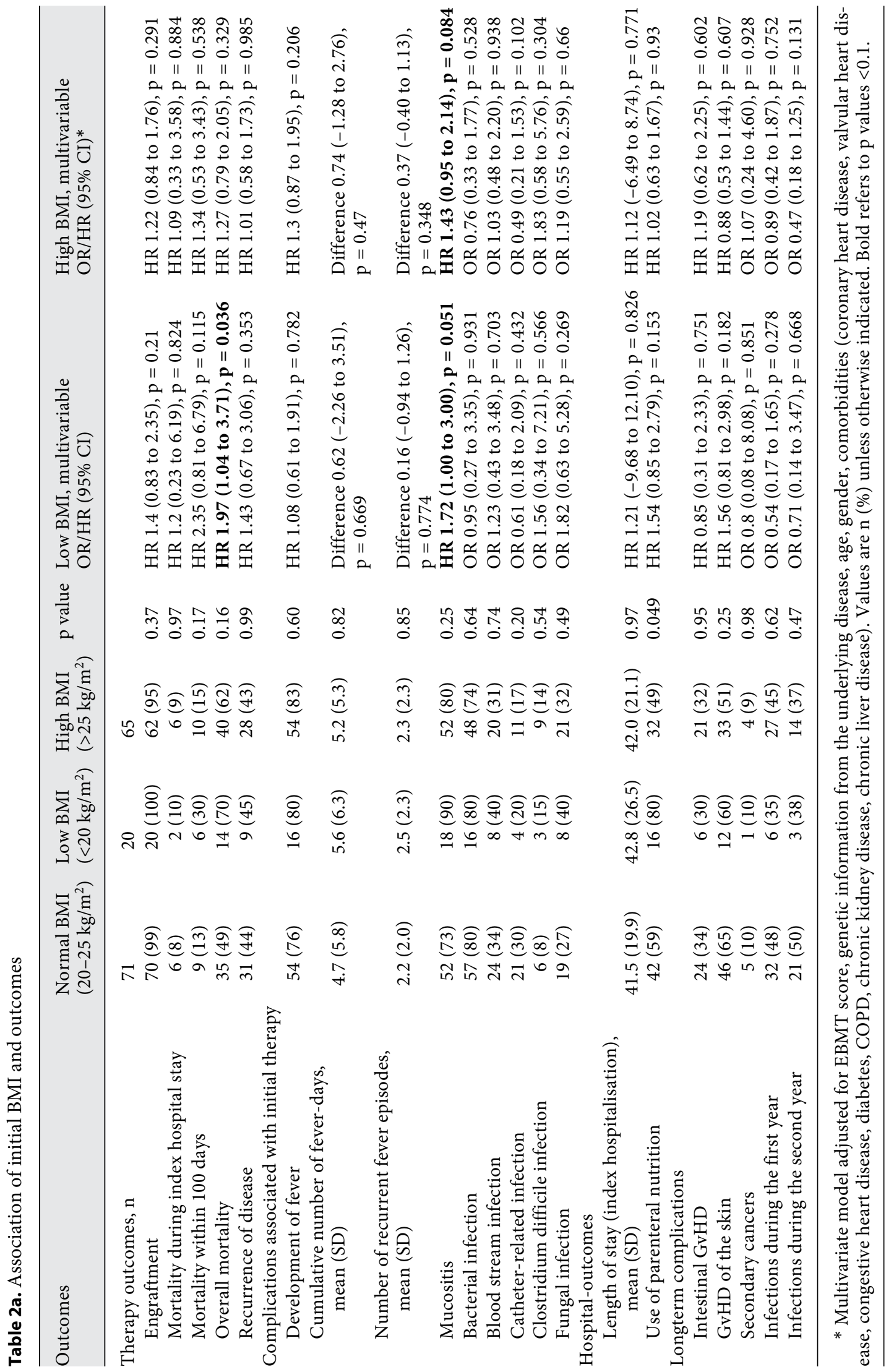




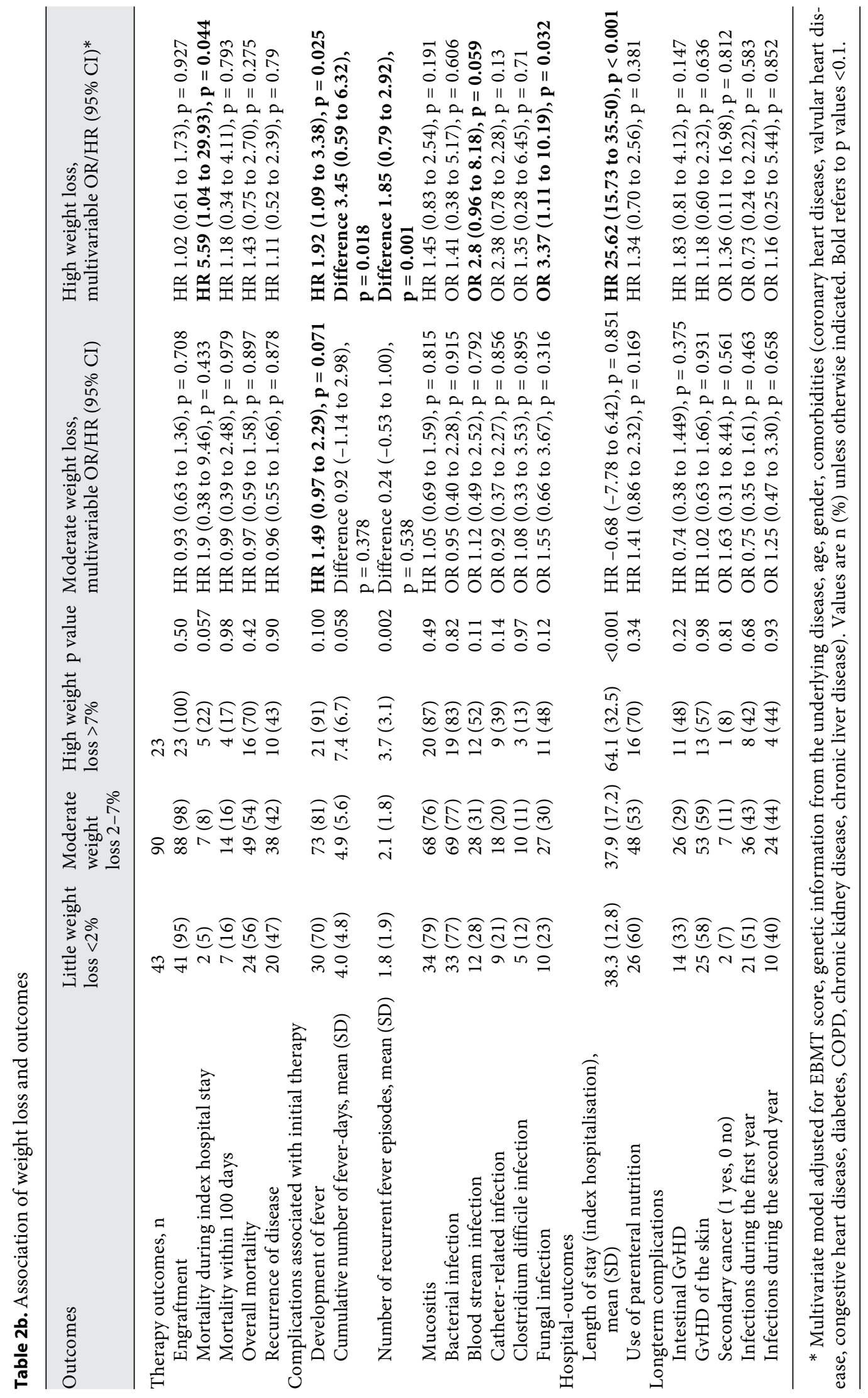


eases [16]. Considerable efforts have been made to standardize nutritional treatment on an inpatient and outpatient basis. National and international consensus committees developed and published guidelines focusing each on distinct medical conditions and different indications [10, 11, 17-26]. Both societies, ASPEN and ESPEN, have published consensus guidelines on screening and nutritional therapy in patients undergoing HSCT [10, 11]. In brief, these guidelines recommend screening for malnutrition and early nutritional interventions if patients are unable to maintain an adequate nutritional intake (energy and proteins) on their own. It is recommended that enteral nutrition should be the first choice feeding route in all patients with inadequate oral food intake and a functioning gastrointestinal tract $[2,3]$; supplemental parenteral nutrition is recommended in patients with inadequate food and enteral intake, for example, patients with severe mucositis (grade $>3$ ), ileus, or intractable vomiting $[2,3]$. Still, there is lack of interventional data demonstrating who among the patient population would benefit most from nutritional interventions as well as regarding the optimal time point to start nutritional therapy, optimal route and optimal products are to be used $[13,27]$. Particularly, the AML patient population has not been studied in great detail. In this study, our analysis focused on nutritional status in AML patients before start of therapy and during HSCT and may help to close this gap.

Our data are in line with previous studies looking at associations of nutritional parameters and outcomes in patients with haematological malignancies. One recent retrospective study from Japan including 145 adult patients who received allogeneic HSCT from 2000 to 2009 reported a step-wise increase in the cumulative incidences of 2-year non-relapse mortality from $3.8 \%$ in the normal group up to $27.3 \%$ in the severe malnutrition group defined based on the post-HSCT weight loss of $>10 \%$ [28]. The same researchers also found that underweight patients before HSCT was a risk factor for mortality with a roughly $10 \%$ increase in risk [29]. Our data validate these findings focusing on a specific patient group, that is, patients with AML and also reporting a variety of different outcomes including mortality, infectious complications and GvHD among others.

In exploratory analyses, we did also investigate associations of nutritional treatment as well glutamine use with outcomes. Importantly, because deterioration of nutritional status is a strong risk predictor for adverse outcome and patients receiving nutrition support in routine medical care in our analysis are per se at higher complica-

Association of Nutritional Parameters in

Patients with AML Undergoing HSCT tion risk, we adjusted our analysis for important prognostic indicators including the EBMT risk score, cytogenetics and comorbidities, as well as body weight before and during HSCT. In the adjusted analysis, we did not find that nutritional therapy would reduce the risks associated with inadequate nutritional status but that in fact outcomes were worse, and additional glutamine treatment did not show any effects on outcomes. Because of the observational design and residual confounding, the interpretation of these results is challenging, maybe even misleading and, thus, must be considered hypothesis-generating only. Nevertheless, this calls for larger randomised trials to investigate the effects of nutritional interventions in this high-risk patient population to establish causal effects.

This report has limitations. First, this was a retrospective analysis of a prospective monocenter cohort study. Follow-up was based on clinical visits during routine medical care and variable in patients. Second, we focus on weight and weight loss only but did not investigate other nutritional parameters including body impedance analysis among others, which may help to better assess detailed body composition [30]. Third, for our exploratory analysis regarding parenteral nutrition and use of glutamine, patients were not randomised and despite adjustment for important prognostic indicators residual confounding is likely. Therefore, this analysis shows associations but does not suggest causality. Prospective interventional trials are needed to better understand the impact of nutritional interventions in this vulnerable patient population.

In conclusion, in patients with AML, low initial BMI and more pronounced weight loss during HSCT are strong prognostic indicators associated with lower survival and worse disease outcomes. Intervention research is needed to investigate whether adequate nutritional therapy can reverse these associations.

\section{Disclosure Statement}

P.S. and Z.S. received research grants from Nestle and Abbott. All other authors confirm that they do not have a conflict of interest associated with this manuscript.

\section{Funding}

This study was supported in part by the Swiss National Science Foundation (SNSF Professorship, PP00P3_150531/1) and the Research Council of the Kantonsspital Aarau (1410.000.044). 


\section{Appendix}

Appendix 1. Association of parenteral nutrition and outcomes

\begin{tabular}{|c|c|c|c|c|}
\hline Outcomes & $\begin{array}{l}\text { No parenteral } \\
\text { nutrition }\end{array}$ & $\begin{array}{l}\text { Parenteral } \\
\text { nutrition }\end{array}$ & $\mathrm{p}$ value & $\begin{array}{l}\text { Use of parenteral nutrition, } \\
\text { multivariable OR/HR }(95 \% \mathrm{CI}) *\end{array}$ \\
\hline Therapy outcomes, $\mathrm{n}$ & 66 & 90 & & \\
\hline Engraftment & $62(94)$ & $90(100)$ & 0.018 & HR $1.35(0.95-1.93), p=0.096$ \\
\hline Mortality during index hospital stay & $1(2)$ & $13(14)$ & 0.005 & HR $9.48(1.14-79.04), p=0.038$ \\
\hline Mortality within 100 days & $5(8)$ & $20(22)$ & 0.014 & HR $3.06(1.07-8.77), p=0.038$ \\
\hline Overall mortality & $36(55)$ & $53(59)$ & 0.59 & HR $1.39(0.88-2.22), \mathrm{p}=0.162$ \\
\hline Recurrence of disease & $31(47)$ & $37(41)$ & 0.47 & HR $1.14(0.68-1.93), \mathrm{p}=0.618$ \\
\hline \multicolumn{5}{|l|}{ Complications associated with initial therapy } \\
\hline Development of fever & $43(65)$ & $81(90)$ & $<0.001$ & HR $1.91(1.27-2.87), p=0.002$ \\
\hline Cumulative number of fever-days, mean (SD) & $2.2(2.9)$ & $7.1(6.3)$ & $<0.001$ & Difference $4.83(3.06-6.61), p<0.001$ \\
\hline Number of recurrent fever episodes, mean (SD) & $1.2(1.3)$ & $3.1(2.3)$ & $<0.001$ & Difference $1.83(1.16-2.49), \mathrm{p}<0.001$ \\
\hline Mucositis & $34(52)$ & $88(98)$ & $<0.001$ & HR $5.64(3.55-8.95), p=0.000$ \\
\hline Bacterial infection & $48(73)$ & $73(81)$ & 0.21 & OR $1.67(0.71-3.92), p=0.236$ \\
\hline Blood stream infection & $18(27)$ & $34(38)$ & 0.17 & OR $1.66(0.76-3.65), \mathrm{p}=0.207$ \\
\hline Catheter-related infection & $13(20)$ & $23(26)$ & 0.39 & OR $1.46(0.61-3.51), \mathrm{p}=0.393$ \\
\hline Clostridium difficile infection & $4(6)$ & $14(16)$ & 0.067 & OR $4.06(1.11-14.86), p=0.035$ \\
\hline Fungal infection & $13(20)$ & $35(39)$ & 0.010 & OR $2.95(1.26-6.88), p=0.012$ \\
\hline \multicolumn{5}{|l|}{ Hospital-outcomes } \\
\hline Length of stay (index hospitalisation), mean (SD) & $32.9(9.4)$ & $48.4(24.8)$ & $<0.001$ & HR $14.10(7.67-20.53), p<0.001$ \\
\hline \multicolumn{5}{|l|}{ Longterm complications } \\
\hline Intestinal GvHD & $12(18)$ & $39(43)$ & $<0.001$ & HR $2.38(1.19-4.74), p=0.014$ \\
\hline GvHD of the skin & $28(42)$ & $63(70)$ & $<0.001$ & HR $1.99(1.21-3.25), p=0.006$ \\
\hline Secondary cancer & $4(8)$ & $6(11)$ & 0.55 & OR $1.49(0.25-8.70), \mathrm{p}=0.658$ \\
\hline Infections during the first year & $35(56)$ & $30(38)$ & 0.031 & OR $0.47(0.23-1.00), p=0.049$ \\
\hline Infections during the second year & $24(56)$ & $14(31)$ & 0.019 & OR $0.35(0.13-0.94), p=0.037$ \\
\hline
\end{tabular}

* Multivariate model adjusted for for EBMT score, genetic information from the underlying disease, age, gender, comorbidities (coronary heart disease, valvular heart disease, congestive heart disease, diabetes, COPD, chronic kidney disease, chronic liver disease), initial BMI and weight loss.

Values are n (\%) unless otherwise indicated. Bold refers to $\mathrm{p}$ values $<0.1$.

Appendix 2. Association of glutamine use and outcomes in patients with parenteral nutrition

\begin{tabular}{|c|c|c|c|c|}
\hline Outcomes & No glutamine & Glutamine & $\mathrm{p}$ value & $\begin{array}{l}\text { Use of glutamin, } \\
\text { multivariable OR/HR ( } 95 \% \mathrm{CI})^{*}\end{array}$ \\
\hline Therapy outcomes, $\mathrm{n}$ & 36 & 54 & & \\
\hline Engraftment & $36(100)$ & $54(100)$ & & HR $0.52(0.31$ to 0.85$), p=0.009$ \\
\hline Mortality during index hospital stay & $5(14)$ & $8(15)$ & 0.90 & HR $0.81(0.21$ to 3.12$), p=0.754$ \\
\hline Mortality within 100 days & $9(25)$ & $11(20)$ & 0.60 & HR 0.53 ( 0.19 to 1.49$), \mathrm{p}=0.230$ \\
\hline Overall mortality & $22(61)$ & $31(57)$ & 0.73 & HR $0.88(0.47$ to 1.62$), \mathrm{p}=0.678$ \\
\hline Recurrence of disease & $14(39)$ & $23(43)$ & 0.73 & HR 0.75 ( 0.35 to 1.59$), \mathrm{p}=0.449$ \\
\hline \multicolumn{5}{|l|}{ Complications associated with initial therapy } \\
\hline Development of fever & $34(94)$ & $47(87)$ & 0.25 & HR 0.85 ( 0.52 to 1.39$), p=0.517$ \\
\hline Cumulative number of fever-days, mean (SD) & $7.0(6.3)$ & $7.1(6.3)$ & 0.96 & Difference -0.28 ( -3.26 to 2.69$), p=0.850$ \\
\hline Number of recurrent fever episodes, mean (SD) & $3.0(2.0)$ & $3.1(2.5)$ & 0.73 & Difference -0.09 ( -1.18 to 1.01$), p=0.877$ \\
\hline Mucositis & $36(100)$ & $52(96)$ & 0.24 & HR $0.47(0.28$ to 0.78$), p=0.004$ \\
\hline Bacterial infection & $28(78)$ & $45(83)$ & 0.51 & OR $1.81(0.53$ to 6.16$), p=0.345$ \\
\hline Blood stream infection & $12(33)$ & $22(41)$ & 0.48 & OR $1.74(0.63$ to 4.82$), \mathrm{p}=0.283$ \\
\hline
\end{tabular}




\begin{tabular}{|c|c|c|c|c|}
\hline Catheter-related infection & $9(25)$ & $14(26)$ & 0.92 & OR $1.15(0.37$ to 3.59$), p=0.806$ \\
\hline Clostridium difficile infection & $2(6)$ & $12(22)$ & 0.033 & OR $4.15(0.70$ to 24.67$), \mathrm{p}=0.118$ \\
\hline Fungal infection & $14(39)$ & $21(39)$ & 1.00 & OR $0.92(0.32$ to 2.66$), \mathrm{p}=0.881$ \\
\hline Hospital-outcomes & & & & \\
\hline $\begin{array}{l}\text { Length of stay (index hospitalisation), mean (SD) } \\
\text { Longterm complications }\end{array}$ & $50.3(26.4)$ & $47.1(23.8)$ & 0.55 & HR $-3.86(-14.35$ to 6.64$), p=0.466$ \\
\hline Intestinal GvHD & $13(36)$ & $26(48)$ & 0.26 & HR 1.21 ( 0.56 to 2.64$), p=0.628$ \\
\hline GvHD of the skin & $27(75)$ & $36(67)$ & 0.40 & HR $0.56(0.31$ to 0.99$), p=0.047$ \\
\hline Secondary cancers & $2(11)$ & $4(12)$ & 0.89 & OR $2.23(0.23$ to 21.40$), \mathrm{p}=0.486$ \\
\hline Infections during the first year & $4(12)$ & $26(55)$ & $<0.001$ & OR $14.13(3.02$ to 66.06$), p=0.001$ \\
\hline Infections during the second year & $3(17)$ & $11(41)$ & 0.087 & OR $7.37(0.78$ to 70.08$), p=0.082$ \\
\hline
\end{tabular}

* Multivariate model adjusted for EBMT score, genetic information from the underlying disease, age, gender, comorbidities (coronary heart disease, valvular heart disease, congestive heart disease, diabetes, COPD, chronic kidney disease, chronic liver disease), initial BMI and weight loss.

Values are $\mathrm{n}(\%)$ unless otherwise indicated. Bold refers to $\mathrm{p}$ values $<0.1$.

\section{References}

1 Schutz P, Bally M, Stanga Z, Keller U: Loss of appetite in acutely ill medical inpatients: physiological response or therapeutic target? Swiss Med Wkly 2014;144:w13957.

2 Bozzetti F: Re: A.S.P.E.N. clinical guidelines: nutrition support therapy during adult anticancer treatment and in hematopoietic cell transplantation. JPEN J Parenter Enteral Nutr 2010;34:455; author reply 456.

3 Bozzetti F, Arends J, Lundholm K, Micklewright A, Zurcher G, Muscaritoli M: ESPEN guidelines on parenteral nutrition: non-surgical oncology. Clin Nutr 2009;28:445-454.

4 Kuhlmann MK, Levin NW: Potential interplay between nutrition and inflammation in dialysis patients. Contrib Nephrol 2008;161: 76-82.

5 Oner-Iyidogan Y, Gurdol F, Kocak H, et al: Appetite-regulating hormones in chronic kidney disease patients. J Ren Nutr 2011;21: 316-321.

6 Schuetz P: 'Eat your lunch!' - controversies in the nutrition of the acutely, non-critically ill medical inpatient. Swiss Med Wkly 2015; 145:w14132.

7 Urbain P, Birlinger J, Lambert C, Finke J, Bertz H, Biesalski HK: Longitudinal followup of nutritional status and its influencing factors in adults undergoing allogeneic hematopoietic cell transplantation. Bone Marrow Transplant 2013;48:446-451.

8 Arends J, Zuercher G, Dossett A, et al: Nonsurgical oncology - guidelines on parenteral nutrition, chapter 19. Ger Med Sci 2009;7: Doc09.
9 Arends J: [Cancer patients need safe and efficient nutrition]. Krankenpfl J 2005;43: 130.

10 August DA, Huhmann MB; American Society for Parenteral and Enteral Nutrition (A.S.P.E.N.) Board of Directors: A.S.P.E.N. clinical guidelines: nutrition support therapy during adult anticancer treatment and in hematopoietic cell transplantation. JPEN J Parenter Enteral Nutr 2009;33:472-500.

11 Arends J, Bodoky G, Bozzetti F, et al: ESPEN guidelines on enteral nutrition: non-surgical oncology. Clin Nutr 2006;25:245-259.

12 Kondrup J, Rasmussen HH, Hamberg O, Stanga Z: Nutritional risk screening (NRS 2002): a new method based on an analysis of controlled clinical trials. Clin Nutr 2003;22: 321-336.

13 Bally MR, Blaser Yildirim PZ, Bounoure L, et al: Nutritional support and outcomes in malnourished medical inpatients: a systematic review and meta-analysis. JAMA Intern Med 2016;176:43-53.

14 O'Meara A, Holbro A, Meyer S, et al: Forty years of haematopoietic stem cell transplantation: a review of the Basel experience. Swiss Med Wkly 2014;144:w13928.

15 von Elm E, Altman DG, Egger M, et al: The strengthening the reporting of observational studies in epidemiology (STROBE) statement: guidelines for reporting observational studies. Gac Sanit 2008;22:144-150.

16 Felder S, Lechtenboehmer C, Bally M, et al: Association of nutritional risk and adverse medical outcomes across different medical inpatient populations. Nutrition 2015;31: 1385-1393.

17 Brown RO, Compher C: A.S.P.E.N. clinical guidelines: nutrition support in adult acute and chronic renal failure. JPEN J Parenter Enteral Nutr 2010;34:366-377.

18 Cano NJ, Aparicio M, Brunori G, et al: ESPEN guidelines on parenteral nutrition: adult renal failure. Clin Nutr 2009;28:401-414.

19 Choban P, Dickerson R, Malone A, Worthington P, Compher C: A.S.P.E.N. clinical guidelines: nutrition support of hospitalized adult patients with obesity. JPEN J Parenter Enteral Nutr 2013;37:714-744.

20 McMahon MM, Nystrom E, Braunschweig C, Miles J, Compher C: A.S.P.E.N. clinical guidelines: nutrition support of adult patients with hyperglycemia. JPEN J Parenter Enteral Nutr 2013;37:23-36.

21 Mueller C, Compher C, Ellen DM: A.S.P.E.N. clinical guidelines: nutrition screening, assessment, and intervention in adults. JPEN J Parenter Enteral Nutr 2011;35:16-24.

22 Plauth M, Cabre E, Riggio O, et al: ESPEN guidelines on enteral nutrition: liver disease. Clin Nutr 2006;25:285-294.

23 Sobotka L, Schneider SM, Berner YN, et al: ESPEN guidelines on parenteral nutrition: geriatrics. Clin Nutr 2009;28:461-466.

24 Vanek VW, Borum P, Buchman A, et al: A.S.P.E.N. position paper: recommendations for changes in commercially available parenteral multivitamin and multi-trace element products. Nutr Clin Pract 2012;27: 440-491. 
25 Vanek VW, Matarese LE, Robinson M, Sacks GS, Young LS, Kochevar M: A.S.P.E.N. position paper: parenteral nutrition glutamine supplementation. Nutr Clin Pract 2011;26: 479-494.

26 Volkert D, Berner YN, Berry E, et al: ESPEN guidelines on enteral nutrition: geriatrics. Clin Nutr 2006;25:330-360.

27 Kiss N, Seymour JF, Prince HM, Dutu G: Challenges and outcomes of a randomized study of early nutrition support during autologous stem-cell transplantation. Curr Oncol 2014;21:e334-e339.

28 Fuji S, Mori T, Khattry N, et al: Severe weight loss in 3 months after allogeneic hematopoietic SCT was associated with an increased risk of subsequent non-relapse mortality. Bone Marrow Transplant 2015;50:100-105.

29 Fuji S, Takano K, Mori T, et al: Impact of pretransplant body mass index on the clinical outcome after allogeneic hematopoietic SCT. Bone Marrow Transplant 2014;49:15051512.

30 Felder S, Braun N, Stanga Z, Kulkarni P, Faessler L, Kutz A, et al: Unraveling the link between malnutrition and adverse clinical outcomes: association of acute and chronic malnutrition measures with blood biomarkers from different pathophysiological states. Ann Nutr Metab 2016;68:164-172. 